\title{
Atomic layer deposition of InN using trimethylindium and ammonia plasma
}

Petro Deminskyi, Polla Rouf, Ivan Gueorguiev Ivanov and Henrik Pedersen

The self-archived postprint version of this journal article is available at Linköping University Institutional Repository (DiVA):

http://urn.kb.se/resolve?urn=urn:nbn:se:liu:diva-15.5541

N.B.: When citing this work, cite the original publication.

Deminskyi, P., Rouf, P., Ivanov, I. G., Pedersen, H., (2019), Atomic layer deposition of InN using trimethylindium and ammonia plasma, Journal of Vacuum Science \& Technology. A. Vacuum, Surfaces, and Films, 37(2), 020926. https://doi.org/10.1116/1.5079279

Original publication available at:

https://doi.org/10.1116/1.5079279

Copyright: AIP Publishing

http://www.aip.org/ 


\title{
Atomic layer deposition of InN using trimethylindium and ammonia plasma
}

\author{
Petro Deminskyia), Polla Rouf, Ivan G. Ivanov, Henrik Pedersen \\ Department of Physics, Chemistry and Biology, Linköping University, SE-58183 Linköping, \\ Sweden \\ a) Electronic mail: petro.deminskyi@liu.se
}

$\mathrm{InN}$ is a low band gap, high electron mobility semiconductor material of interest to optoelectronics and telecommunication. Such applications require the deposition of uniform crystalline InN thin films on large area substrates, with deposition temperatures compatible with this temperature-sensitive material. As conventional chemical vapor deposition (CVD) struggles with the low temperature tolerated by the InN crystal, we hypothesize that a time-resolved, surface-controlled CVD route could offer a way forward for InN thin film deposition. In this work, we report atomic layer deposition of crystalline, wurtzite $\mathrm{InN}$ thin films using trimethylindium and ammonia plasma on $\mathrm{Si}(100)$. We found a narrow ALD window of $240-260{ }^{\circ} \mathrm{C}$ with a deposition rate of $0.36 \AA$ /cycle and that the flow of ammonia into the plasma is an important parameter for the crystalline quality of the film. X-ray diffraction measurements further confirmed the polycrystalline nature of InN thin films. X-ray photoelectron spectroscopy measurements show nearly stoichiometric InN with low carbon level $(<1$ atomic \%) and oxygen level $(<5$ atomic $\%)$ in the film bulk. The low carbon level is attributed to a favorable surface chemistry enabled by the $\mathrm{NH}_{3}$ plasma. The film bulk oxygen content is attributed to oxidation upon exposure to air via grain boundary diffusion and possibly by formation of oxygen containing species in the plasma discharge.

\section{INTRODUCTION}

Indium nitride $(\mathrm{InN})$ has interesting optical and electronic properties such as low energy band-gap $(0.7 \mathrm{eV})$, very high electron mobility (theoretical maximum 
$\left.\sim 400 \mathrm{~cm}^{2} / \mathrm{V} \times \mathrm{s}\right)$ and high electron saturation velocity $\left(4.2 \times 10^{7} \mathrm{~cm} / \mathrm{s}\right)$ making it an attractive material for e.g. high frequency electronics and lasers. ${ }^{1,2}$ Chemical vapor deposition (CVD) of $\mathrm{InN}$ using trimethylindium, $\left(\mathrm{In}\left(\mathrm{CH}_{3}\right)_{3}, \mathrm{TMI}\right)$ and ammonia $\left(\mathrm{NH}_{3}\right)$, as precursors is limited by the thermal stability of the $\mathrm{InN}$ crystal above $500{ }^{\circ} \mathrm{C}$, as it decomposes to In metal and $\mathrm{N}_{2}$ gas at those temperatures. ${ }^{3}$ This combined with the TMI decomposition (that occurs homogeneously in the temperature range $\left.120-535^{\circ} \mathrm{C}\right),{ }^{4}$ and low reactivity of $\mathrm{NH}_{3}$ at temperatures below $500{ }^{\circ} \mathrm{C},{ }^{5}$ force the use of N/In ratios as high as $10^{5}$ in CVD of InN. ${ }^{6}$ We hypothesize that a better route would be a surface-controlled CVD process where the role of the gas phase chemistry is strongly reduced or even eliminated. A time-resolved CVD route, where the In and $\mathrm{N}$ precursors are separated in time to promote a kineticallycontrolled pulsed process, could be such a route. Therefore, a time-resolved CVD process in the form of atomic layer deposition (ALD) for InN was explored. Given the low reactivity of ammonia at low temperatures, a nitrogen containing plasma has been used in previous studies for ALD of both polycrystalline and epitaxial InN on different planar and 3D substrate topographies. ${ }^{7-11}$ The literature on InN ALD uses mainly TMI as In precursor, with InCp as a notable exception. ${ }^{12}$ It has been shown that Ar- $\mathrm{N}_{2}$ plasma and TMI, results in a poorly functioning surface chemistry for removal of methyl groups from the surface, and requires very long plasma exposures, up to $120 \mathrm{~s} .{ }^{9,11}$ Nepal et al. reported a correlation between changes in the gas-phase chemistry of the plasma source and InN film; higher nitrogen atom concentration within the plasma source is correlated with smoother InN films. Furthermore, low $\mathrm{N}_{2}$ flow appears to aid reduction of the carbon content. ${ }^{10}$ The use of ammonia plasma as an alternative nitrogen source for InN ALD has not been fully investigated, although briefly mentioned by Ozgit-Akgun et al. ${ }^{12}$ The approach to InN ALD employing $\operatorname{In}\left(\mathrm{CH}_{3}\right)_{3}$ is interesting since the $\mathrm{NH}_{\mathrm{x}}$ species present in the plasma are believed to remove hydrocarbons from the surface. ${ }^{13}$ In this work, we report on the self-limiting growth of crystalline InN thin films by ALD using TMI and ammonia plasma. Additionally, the impact of ammonia plasma power and ammonia flow on film quality has been investigated, analyzed and described in detail. 


\section{EXPERIMENTAL}

\section{A. Film deposition}

Depositions were carried out in a Picosun R-200 atomic layer deposition tool without load lock chamber with a total pressure of $6 \mathrm{hPa}$. The ICP plasma is generated within a quartz tube surrounded by a cylindrical RF coil. The substrate holder stage is located downstream $(\sim 70 \mathrm{~cm})$ from the plasma source. ALD of $\mathrm{InN}$ were conducted within the temperature range of $200-360^{\circ} \mathrm{C}$ on $2 \times 2 \mathrm{~cm} \mathrm{Si}(100)$ using $\mathrm{NH}_{3}$ plasma, and In $\left(\mathrm{CH}_{3}\right)_{3}$, kept in a stainless-steel bubbler mounted in a Peltier element with the temperature set at $23{ }^{\circ} \mathrm{C} . \mathrm{N}_{2}(99.999 \%)$ was used as the carrier gas for trimethylindium precursor delivery to the reaction chamber. The plasma was ignited using a co-flow of $100 \mathrm{sccm}$ Ar (99.9997\%) together with the $\mathrm{NH}_{3}(99.999990 \%)$ flow. $\mathrm{N}_{2}, \mathrm{Ar}$, and $\mathrm{NH}_{3}$ gases were further purified by getter filters. The gas mixture was fed into the system downstream from the ICP source. Unless stated otherwise, the $\mathrm{NH}_{3}$ flow rate was $50 \mathrm{sccm}$ and the plasma power in the range from $2400 \mathrm{~W}$ to $2800 \mathrm{~W}$ with $10 \mathrm{~s}$ plasma pulses. An AB-type ALD process was used with TMI and $\mathrm{NH}_{3}$ plasma. The TMI vapor pressure is given by Eqn. (1) ${ }^{14}$ :

$$
\log P(\text { Torr })=10.98-\frac{3204}{T(K)},
$$

which gives the vapor pressure of TMI to $1.46 \mathrm{hPa}$ at $23^{\circ} \mathrm{C}$, which is lower than the total pressure in the deposition chamber. We therefore used a bubbler "fill-empty" approach for the TMI exposure: During the first pulse, the fill-pulse, the ALD valve is opened and a high flow of $300 \mathrm{sccm}$ nitrogen carrier gas is passing through the bubbler. The high flow increases the total pressure in the bubbler. The partial pressure of the TMI in the bubbler is not expected to be affected by this. Then in the second pulse, the empty-pulse, the ALD valve is opened to the bubbler and a low flow of $100 \mathrm{sccm}$ nitrogen carrier gas is flown through the bubbler. The high pressure in the bubbler, created by the high nitrogen flow in the fill-pulse, serves to empty the bubbler into the reaction chamber. This can be noted by carefully monitoring the pressure in the growth chamber; a short increase in pressure can be noted during the empty-pulse. The two pulses are separated by $10 \mathrm{~s}$ to allow gas mixing in the bubbler. The pulse times used in the fill-empty of the process was $4 \mathrm{~s}$ for the fill sub-pulse and a variable time for the empty sub-pulse. A $10 \mathrm{~s}$ 
purge was used after the TMI fill-empty pulse sequence followed by $10 \mathrm{~s} \mathrm{NH}_{3}$ plasma exposure, unless otherwise noted, and 6 s purge to complete the ALD cycle.

Prior to deposition, the $\mathrm{Si}(100)$ substrate was cleaned in acetone, 2-propanol and deionized (DI) water with further sample drying under $\mathrm{N}_{2}$ flow. Silicon substrates were transferred into the ALD chamber which was held at the set deposition temperature. An in-situ surface pretreatment with $2800 \mathrm{~W} \mathrm{~N}_{2}$ plasma for 2 min was conducted to make the substrate surface somewhat more nitrogen-rich before InN growth. Post-deposition annealing of some InN films was done in the reactor prior to unloading the sample by increasing the temperature to $500{ }^{\circ} \mathrm{C}$ for 2 hours at $10 \mathrm{sccm} \mathrm{N} \mathrm{N}_{2}$ flow.

\section{B. Film characterization}

X-ray diffraction (XRD) analysis was performed by using Empyrean PanAnalytical X'Pert system with a Philips Bragg-Brentano diffractometer that was equipped with a parallel beam detector. The $\mathrm{Cu} \mathrm{K} \alpha$ radiation source $(\lambda=0.154[06] \mathrm{nm})$ was operated at $40 \mathrm{kV}$ and $40 \mathrm{~mA}$. The grazing incidence X-ray diffraction (GIXRD) mode was used to minimize the intensity from the substrate peaks since the films were limited in thickness. The incoming beam angle, $\omega$, was $0.5^{\circ}$. Data were obtained within the $2 \theta$ range of $20-90^{\circ}$, which were performed using $0.02^{\circ}$ step size and $1 \mathrm{~s}$ step time. Interplanar spacing $\left(d_{h k l}\right)$ values were calculated from peaks position using Bragg's law for hexagonal lattice. Lattice parameters $a$ and $c$ were calculated by substituting $d_{h k l}$ values using Eqn. (2).

$$
\frac{1}{d^{2}}=\frac{4}{3}\left(\frac{h^{2}+h k+k^{2}}{a^{2}}\right)+\frac{l^{2}}{c^{2}}
$$

Thickness and film density of the deposited films where measured by a PanAnalytical X'Pert Pro in the X-ray reflectometry (XRR) mode. Growth rates were calculated by dividing film thicknesses by the number of ALD cycles. Surface morphologies of InN thin films were studied using a high-resolution LEO 1550 Gemini field emission SEM. Chemical composition and bonding states of the films were determined by an Axis Ultra DLD instrument from Kratos Analytical X-ray photoelectron spectroscopy (XPS) with a base pressure of $1.1 \times 10^{-9}$ Torr $\left(1.5 \times 10^{-7} \mathrm{~Pa}\right)$ and monochromatic Al $\mathrm{K}_{\mathrm{a}}$ source $\left(\mathrm{h}_{\mathrm{v}}=1486.6 \mathrm{eV}\right)$. Depth profiling was carried out using an $\mathrm{Ar}$ ion sputter beam with an acceleration voltage, spot size, and a sputtering time 
duration of $0.5 \mathrm{kV}, 300 \times 700 \mu \mathrm{m}$, and $400 \mathrm{~s}$ respectively. Spectra deconvolution and quantification were performed using Casa XPS software.

The Raman spectra are measured in a micro-Raman setup in the wavelength range $72-1624 \mathrm{~cm}^{-1}$ using excitation of $532 \mathrm{~nm}$. The laser (with power of $1 \mathrm{~mW}$ to avoid thermal damage to the sample) is focused on the sample to a spot of diameter $\sim 0.85 \mu \mathrm{m}$ using a microscope objective with magnification $100 \mathrm{X}$ and numerical aperture 0.95 . The detection of the spectra is done with a single monochromator (Jobin-Yvon, Model HR460) equipped with a 1200 grooves/mm grating and a CCD camera. The resulting resolution of the system is $\sim 2.5 \mathrm{~cm}^{-1}$. Owing to the small thickness of the $\mathrm{InN}$ layers, the spectrum is strongly dominated by the Raman scattering from the Si-substrate. Nevertheless, it is possible to distinguish clearly the contribution from the InN layer, as will be discussed later.

Ellipsometric spectra of the films were recorded in the wavelength range of 200$1500 \mathrm{~nm}$ at three angles of incidence $\left(65^{\circ}, 70^{\circ}\right.$, and $\left.75^{\circ}\right)$ by using a variable angle spectroscopic ellipsometer (J.A. Woollam). Optical constants of the InN thin films were modeled by the Tauc-Lorentz function as an oscillator. The absorption coefficient,

$$
\alpha(\lambda)=\frac{4 \pi k(\lambda)}{\lambda}
$$

was calculated from the values of the extinction coefficient $k(\lambda)$ determined from the measured ellipsometry data. Optical band gap $\left(E_{g}\right)$ is expressed by the following equation for direct band gap materials and was analytically extracted via extrapolation of the linear part of the absorption spectrum to $(\alpha E)^{2}=0$, where $E$ denotes the photon energy.

$$
\alpha E=A\left(E-E_{g}\right)^{1 / 2} .
$$

\section{Plasma characterization}

Optical emission spectroscopy (OES) was performed using the Mechelle 900 Spectrometer with cooled digital 12-bit CCD camera system with a wavelength range of UV-NIR (200-1100 nm), mounted perpendicularly to the plasma source. Light emitted from the $\mathrm{NH}_{3}$ plasma was collected and directed to a monochromator with an optical fiber cable. The optical emission from the plasma was measured just after the ICP source in the gas flow direction, before the plasma reached the substrate. Data was analyzed with consideration for spectrometer spectral resolution of 900 (meaning that two wavelengths separated by 1/900 of 
the wavelength can be resolved). The measure of resolution is a constant of the instrument, which implies that the fractional wavelength resolution does not vary with the wavelength. The plasma diagnostics were focused on the formation of $\mathrm{NH}, \mathrm{N}_{2}, \mathrm{~N}_{2}{ }^{+}$, and $\mathrm{H}$, at different plasma power, $\mathrm{NH}_{3}$ flow rate, and their influence on $\mathrm{InN}$ properties.

\section{RESULTS AND DISCUSSION}

The InN deposition process was studied by varying the second sub-pulse, i.e. the empty sub-pulse of the TMI fill-empty pulse between 0 and $6 \mathrm{~s}$, while keeping the fill sub-pulse at $4 \mathrm{~s}$ and the $\mathrm{NH}_{3}$ pulse at $10 \mathrm{~s}$, or by keeping the fill sub-pulse at $4 \mathrm{~s}$, the empty sub-pulse at $3.5 \mathrm{~s}$ and varying the $\mathrm{NH}_{3}$ plasma pulse between 0 and $20 \mathrm{~s}$. For all experiments, the purge times $(6 \mathrm{~s})$, deposition temperature $\left(300^{\circ} \mathrm{C}\right)$ and plasma power $(2400 \mathrm{~W})$ were kept constant. The conventional ALD cycles with a single step TMI pulse, i.e. only a $4 \mathrm{~s}$ fill sub-pulse, did not afford uniform InN growth on $\operatorname{Si}(100)$ substrates. We ascribe this to insufficient TMI vapor delivery. Figure 1a shows the effect of the time for both the TMI pulse and the $\mathrm{NH}_{3}$ plasma pulse on the growth rate of $\mathrm{InN}$. A second set of experiments (Fig. 1b) studied the effect of the deposition temperature on the InN growth. Here the TMI empty pulse was $3 \mathrm{~s}$ and the $\mathrm{NH}_{3}$ plasma pulse $10 \mathrm{~s}$ while varying the temperature from $200{ }^{\circ} \mathrm{C}$ to $360^{\circ} \mathrm{C}$. 


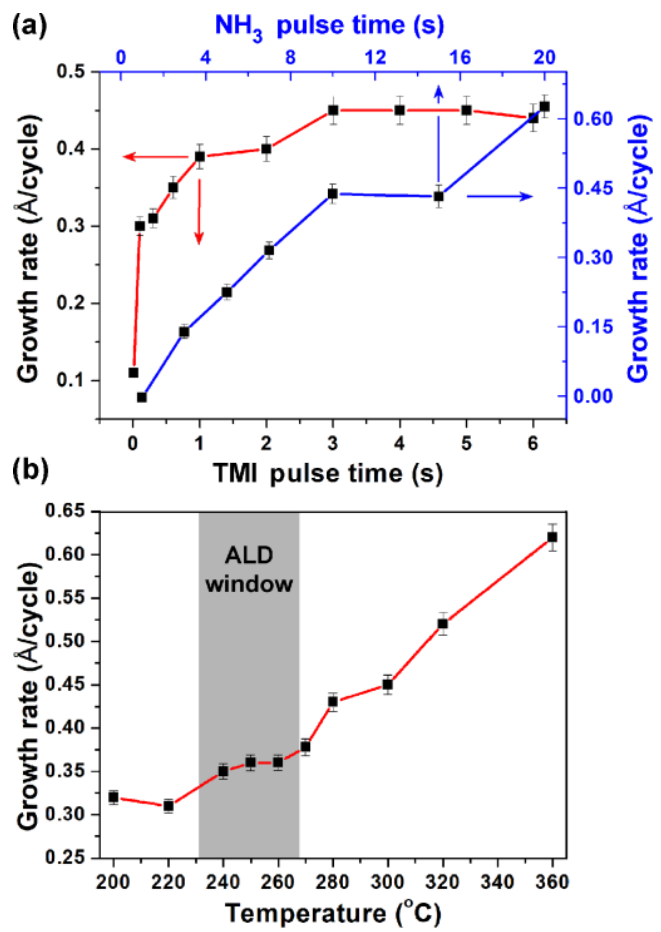

FIG. 1. (a) Effect of TMI and $\mathrm{NH}_{3}$ precursors dose time on $\mathrm{InN}$ growth rate with $2400 \mathrm{~W}$ plasma power at $300{ }^{\circ} \mathrm{C}$ with $10 \mathrm{~s} \mathrm{NH}_{3}$ pulse (red line), and $2800 \mathrm{~W}$ plasma power at $320^{\circ} \mathrm{C}$ with $3.5 \mathrm{~s}$ TMI empty sub-pulse (blue line). (b) Effect of temperature on growth rate, for $3 \mathrm{~s}$ TMI empty sub-pulse and $10 \mathrm{~s} \mathrm{NH}_{3}$ pulse. The TMI fill sub-pulse was $4 \mathrm{~s}$ for all experiments.

The results on InN growth rate as a function of a growth temperature (within 200$360{ }^{\circ} \mathrm{C}$ ) show that $\mathrm{InN}$ is deposited at $200^{\circ} \mathrm{C}$ with $0.32 \AA /$ cycle. The growth rate increases with temperature and shows a narrow plateau of $0.36 \AA$ cycle at $240-260{ }^{\circ} \mathrm{C}$ which could be regarded as a narrow ALD temperature window. It should, however, be noted that the saturation curves are done at higher temperatures, $300{ }^{\circ} \mathrm{C}$ and $320^{\circ} \mathrm{C}$, demonstrating that the deposition chemistry is self-limiting also at these higher temperatures. The growth rate then further increases to reach $0.62 \AA /$ cycle at $360{ }^{\circ} \mathrm{C}$ (Fig. 1b). This indicates saturation in growth rate both as a function of the precursor pulse time and of the temperature. The ALD-cycle for further experiments were set to: TMI $4 \mathrm{~s}$ fill sub-pulse and $3.5 \mathrm{~s}$ empty sub-pulse, $10 \mathrm{~s}$ purge, $10 \mathrm{~s} \mathrm{NH}_{3}$ plasma and $6 \mathrm{~s}$ purge.

Figure 3 displays the SEM images of InN morphology for films deposited at $300{ }^{\circ} \mathrm{C}$ with various durations of the TMI empty sub-pulses. Without the use of fill-empty for the 
TMI pulse, the deposition process leads to growth of isolated islands (Fig. 2a). By only adding a $0.1 \mathrm{~s}$ empty sub-pulse, the islands coalesce (Fig. $2 \mathrm{~b}$ ). Longer empty sub-pulses lead to growth of continuous films consisting of smaller and smaller grains with longer time for the empty sub-pulse. We interpret this as insufficient TMI delivery without the empty sub-pulse.
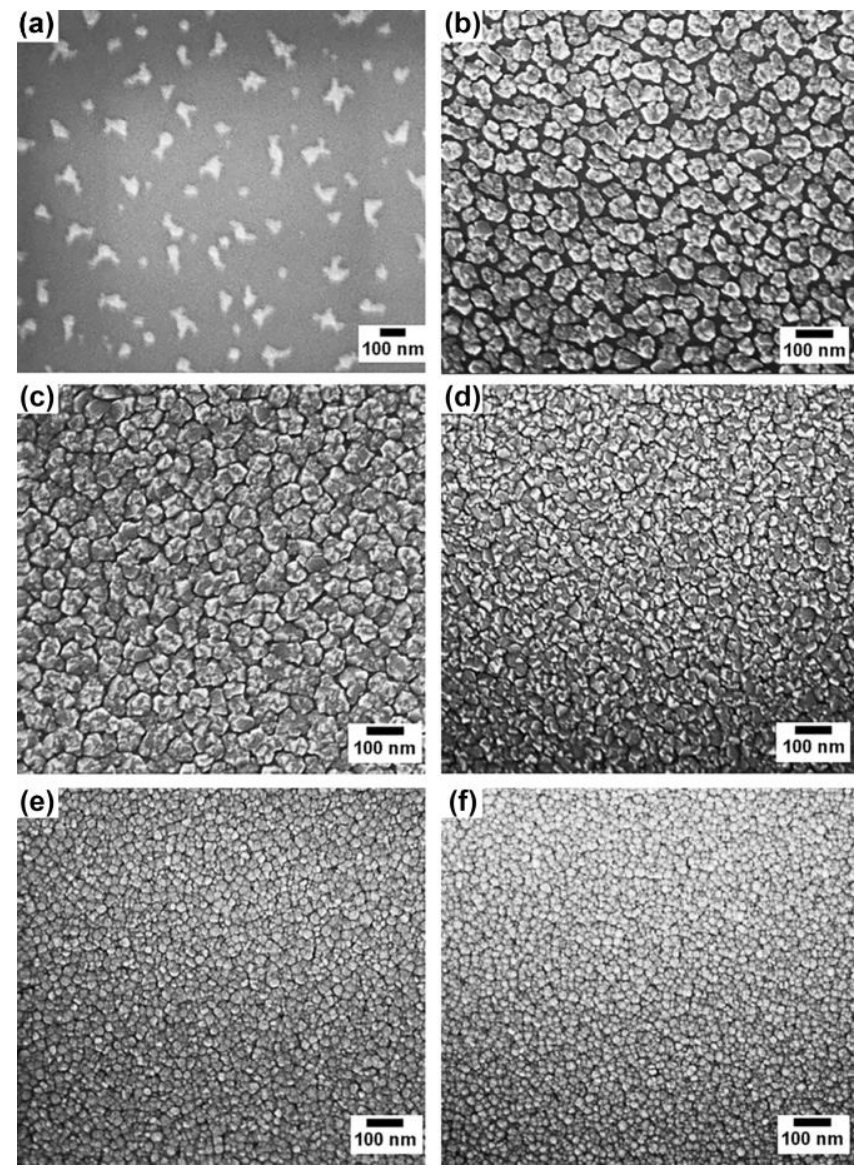

FIG. 2. Top view SEM images of InN film deposited at $300{ }^{\circ} \mathrm{C}$ for various times of the TMI empty sub-pulse: $0 \mathrm{~s}(\mathrm{a}), 0.1 \mathrm{~s} \mathrm{(b),} 0.3 \mathrm{~s}(\mathrm{c}), 0.6 \mathrm{~s}(\mathrm{~d}), 1 \mathrm{~s}(\mathrm{e})$, and $6 \mathrm{~s}$ (f).

Figure 3 displays the SEM images of crystalline grain structures of InN films deposited at $200{ }^{\circ} \mathrm{C}, 260{ }^{\circ} \mathrm{C}, 300{ }^{\circ} \mathrm{C}$, and $360^{\circ} \mathrm{C}$ with $2400 \mathrm{~W}$ plasma power. Changing the temperature leads to the formation of larger grains and their coalescence into larger clusters and a surface morphology characterized by voids between them especially large voids pronounced at $360^{\circ} \mathrm{C}$. It should be noted here that the aim of this study has been to investigate how to deposit the best possible InN material, suitable for use in electronic devices. For such applications, the crystalline quality and the amount of impurities must 
be reduced. We have therefore focused most of our efforts to a deposition temperature of $320{ }^{\circ} \mathrm{C}$. Figure 4 displays the SEM images of crystalline grain structures of InN films deposited with $2400 \mathrm{~W}, 2500 \mathrm{~W}, 2700 \mathrm{~W}$, and $2800 \mathrm{~W}$ plasma power at $320^{\circ} \mathrm{C}$. Changing the plasma power does not have a clear impact on the film morphology, while the GIXRD shows a change in crystalline quality (Fig. 6b). The growth rate changes somewhat with the plasma power from $0.51 \pm 0.03 \AA /$ cycle at $2400 \mathrm{~W}$ to $0.47 \pm 0.03 \AA$ Acycle at $2800 \mathrm{~W}$. Figure 5 shows SEM images of InN films deposited with $50 \mathrm{sccm}, 75 \mathrm{sccm}, 100 \mathrm{sccm}$ ammonia flow under $2800 \mathrm{~W}$ plasma power at $320^{\circ} \mathrm{C}$. Changing ammonia flow has slight impact on the film morphology in terms of grains crystallization. The GIXRD results and variations of the $a$ - and $c$-axis lattice constants show a change in crystalline quality of InN (Fig. 6b). The growth rate changes somewhat with the ammonia flow from $0.44 \AA /$ cycle at $50 \mathrm{sccm}$ to $0.33 \AA /$ cycle at $100 \mathrm{sccm}$. This could be explained by an increased density of hydrogen radicals in ammonia plasma with higher ammonia flow rate as hydrogen radicals has been shown to reduce the growth rate of InN films. ${ }^{15}$
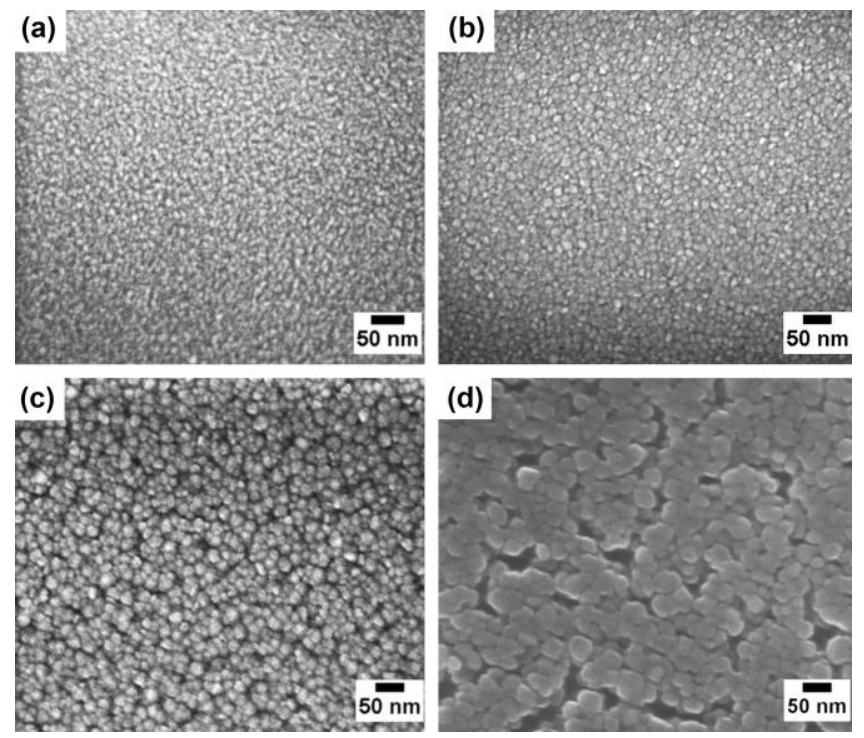

FIG. 3. Top view SEM images of InN films deposited at $200{ }^{\circ} \mathrm{C}$ (a), $260^{\circ} \mathrm{C}$ (b), $300{ }^{\circ} \mathrm{C}(\mathrm{c})$, and $360^{\circ} \mathrm{C}(\mathrm{d})$ with $2400 \mathrm{~W}$ plasma power. 

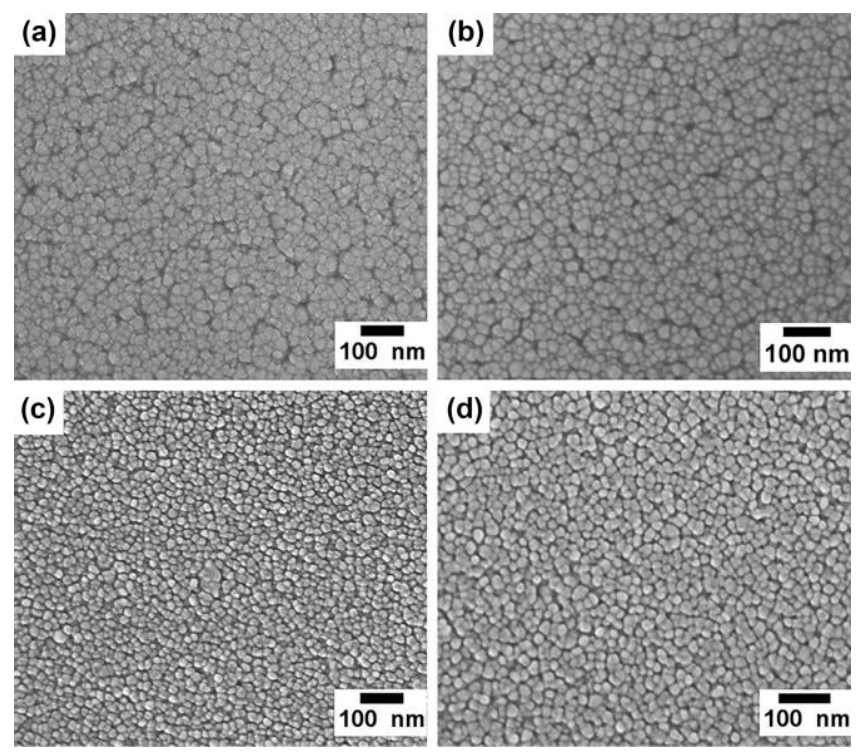

FIG. 4. Top view SEM images of InN films deposited at $2400 \mathrm{~W}$ (a), $2500 \mathrm{~W}$ (b), $2700 \mathrm{~W}(\mathrm{c})$, and $2800 \mathrm{~W}(\mathrm{~d})$ plasma power at $320^{\circ} \mathrm{C}$.
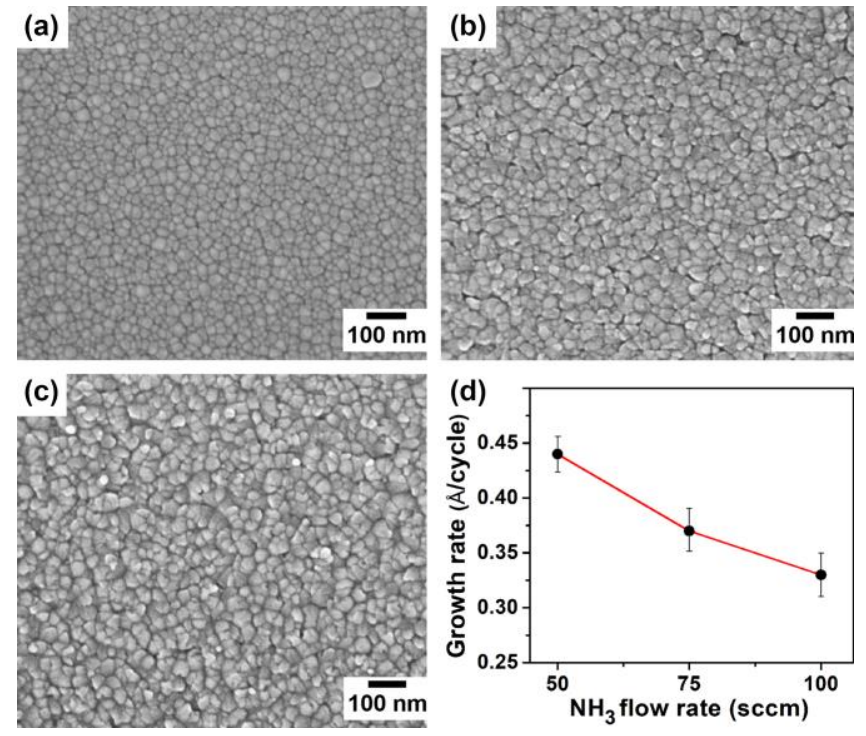

FIG. 5. Top view SEM images of InN films for $50 \mathrm{sccm}$ (a), $75 \mathrm{sccm}$ (b) and $100 \mathrm{sccm}$ (c) of $\mathrm{NH}_{3}$ flow. (d) Effect of $\mathrm{NH}_{3}$ flow on $\mathrm{InN}$ growth rate with $2800 \mathrm{~W}$ plasma power at $320^{\circ} \mathrm{C}$.

The crystallinity of the InN films studied by GIXRD is shown in Figure 6a for $18 \mathrm{~nm}, 26 \mathrm{~nm}$ and $31 \mathrm{~nm}$ thick films deposited with $2400 \mathrm{~W}$ plasma power at $240{ }^{\circ} \mathrm{C}$, $320^{\circ} \mathrm{C}$, and $360{ }^{\circ} \mathrm{C}$, respectively. Figure $6 \mathrm{~b}$ shows the GIXRD measurements of $26 \mathrm{~nm}$, $25 \mathrm{~nm}$ and $23 \mathrm{~nm}$ thick InN films deposited at $320^{\circ} \mathrm{C}$ with $2400 \mathrm{~W}, 2500 \mathrm{~W}$, and $2800 \mathrm{~W}$ 
plasma power, respectively. The (100), (002), (011), (012), (110), (013), (020), (004) and (023) reflections ${ }^{16,17}$ of the hexagonal wurtzite phase of $\mathrm{InN}$ were observed. We note that changes in deposition temperature and plasma power do not alter the peak positions, while the intensity of the peaks increases with increasing deposition temperature. The lattice parameters $a$ and $c$ were calculated using Eqn. (2) and the $2 \theta$ positions of the (002) and (011) reflections (Fig. 7a,b and Fig. 8b). Interplanar spacing $\left(d_{h k l}\right)$ values of (002) and (011) planes were calculated from Bragg's law. The relation between the strain in the $c$ axis direction $\varepsilon_{c}=\left|\left(c-c_{0}\right) / c_{0}\right|$ and that in the direction of the a-axis $\varepsilon_{a}=\left|\left(a-a_{0}\right) / a_{0}\right|$, (where $c_{0}=5.7033 \AA$ and $a_{0}=3.5378 \AA$ correspond to epitaxial $\mathrm{InN}$ ) gives values $\sim 0.004$ for $\varepsilon_{c}$ and 0.002 for $\varepsilon_{a}$ indicating almost fully relaxed and strain free InN films (Fig. 7a,b and Fig. 8b). ${ }^{18,19}$ It should be noted that the strain in the c-axis and a-axis being calculated in all cases is for the individual grains of the polycrystalline material.
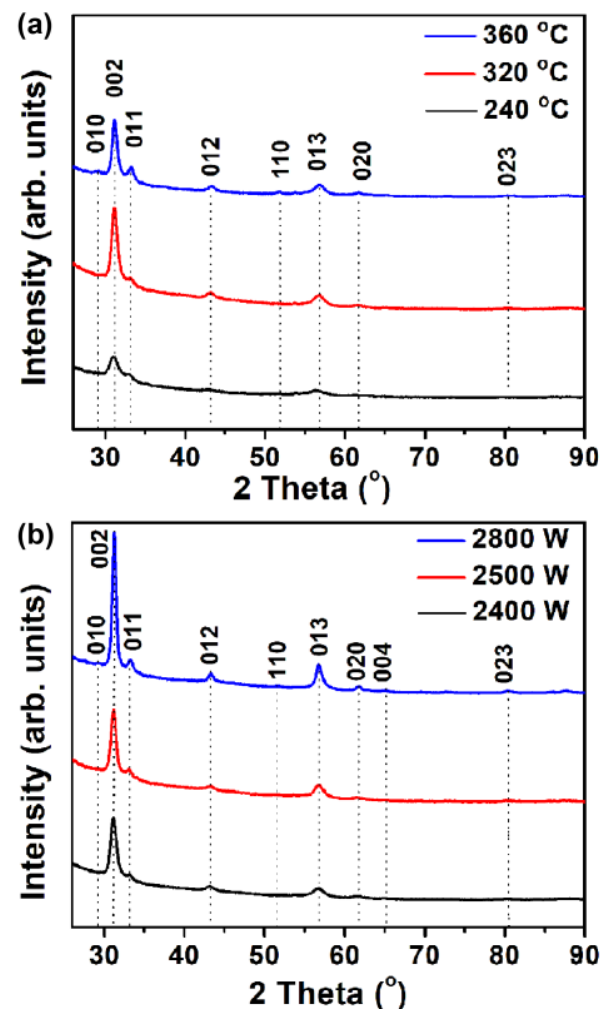

FIG. 6. GIXRD pattern of $\mathrm{InN}$ film deposited on $\mathrm{Si}(100)$ substrate (a) under $240{ }^{\circ} \mathrm{C}$, $320^{\circ} \mathrm{C}, 360^{\circ} \mathrm{C}$ deposition temperatures and $2400 \mathrm{~W}$ plasma power; (b) under $2400 \mathrm{~W}$, $2500 \mathrm{~W}, 2800 \mathrm{~W}$ plasma power and $320^{\circ} \mathrm{C}$ deposition temperature. 
GIXRD of InN thin films grown with $2400 \mathrm{~W} \mathrm{NH}_{3}$ plasma power at $240{ }^{\circ} \mathrm{C}$, $320^{\circ} \mathrm{C}$, and $360^{\circ} \mathrm{C}$ indicated that with higher temperature, the $c$-axis and $a$-axis lattice parameters are shifting towards the values that corresponding to the fully relaxed and strain free InN films (Fig. 7a). Furthermore, the investigation of crystalline quality of InN films grown under $2400 \mathrm{~W}, 2500 \mathrm{~W}, 2800 \mathrm{~W}$ plasma power and $320^{\circ} \mathrm{C}$ deposition temperature indicate that $c$-axis and $a$-axis lattice parameters keep shifting towards $c$ axis and $a$-axis lattice parameters that corresponding to the single crystal InN film (Fig. 7b). GIXRD of $\sim 40 \mathrm{~nm}$ and $\sim 49 \mathrm{~nm} \mathrm{InN} \mathrm{thin} \mathrm{films} \mathrm{grown} \mathrm{with} 2800 \mathrm{~W} \mathrm{NH}_{3}$ plasma power at $320^{\circ} \mathrm{C}$, and $360^{\circ} \mathrm{C}$ with an added annealing at $500{ }^{\circ} \mathrm{C}$ for $2 \mathrm{~h}$ indicated that the annealing affected the relative intensities of the peaks. For the InN films grown at $320^{\circ} \mathrm{C}(\sim 40 \mathrm{~nm})$, and $360^{\circ} \mathrm{C}(\sim 49 \mathrm{~nm})$, the $c$-axis lattice parameter was $5.7140 \AA$ and $5.7058 \AA$ while the $a$-axis lattice parameter was $3.5198 \AA$ and $3.5254 \AA$, showing that the annealing further reduces the stress in the material. GIXRD measurements of InN films grown with different ammonia flows (Fig. 8a, Fig. S1) show that the diffraction peaks intensities increase with higher ammonia flow, and that the $a$ - and $c$ axis lattice have values of $3.5427 \AA$ and $5.6998 \AA$ at the optimal ammonia flow. This indicate slight switch from tensile to compressive strain in the $c$-axis direction for the individual grains of the InN films grown at $75 \mathrm{sccm}$ and $100 \mathrm{sccm} \mathrm{NH}_{3}$ flow, respectively, and an increased crystalline quality of InN with higher ammonia flow in the plasma. All values of $a$ - and $c$-axis lattice parameters are summarized in the Table S1. XRR for $\sim 35 \mathrm{~nm}$-thick $\mathrm{InN}$ film deposited with $100 \mathrm{sccm} \mathrm{NH}$ flow under $2800 \mathrm{~W}$ plasma power at $320{ }^{\circ} \mathrm{C}$ reveals film density of $6.47 \mathrm{~g} / \mathrm{cm}^{3}$ which is in agreement with previously reported values. ${ }^{9,20}$ 


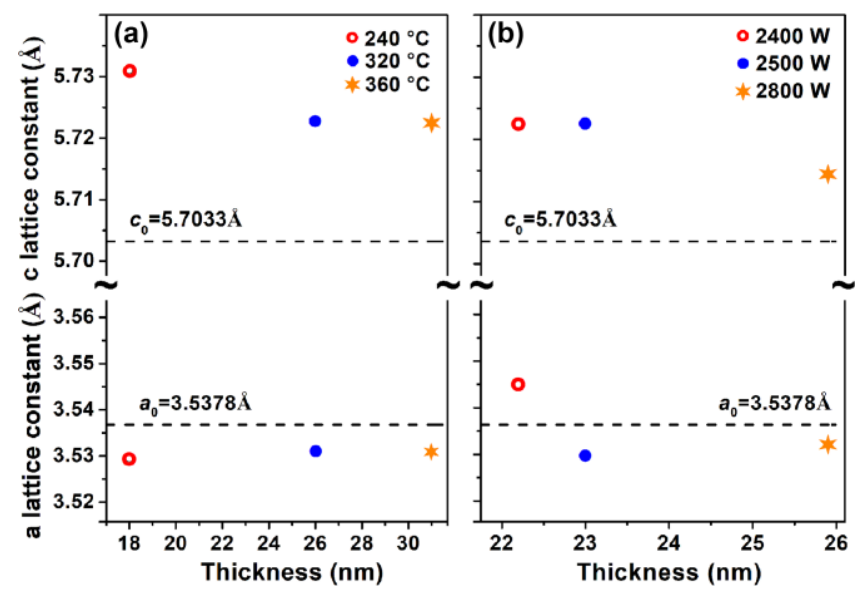

FIG. 7. Variations of the $a$ - and $c$-axis lattice constants of In- and N-growth face InN films with the film thickness at (a) different temperatures at $2400 \mathrm{~W} \mathrm{NH}_{3}$ plasma, and (b) different plasma power at $320^{\circ} \mathrm{C}$. Dashed lines show strain-free lattice constant of the $a$ and $c$-axis. ${ }^{18}$
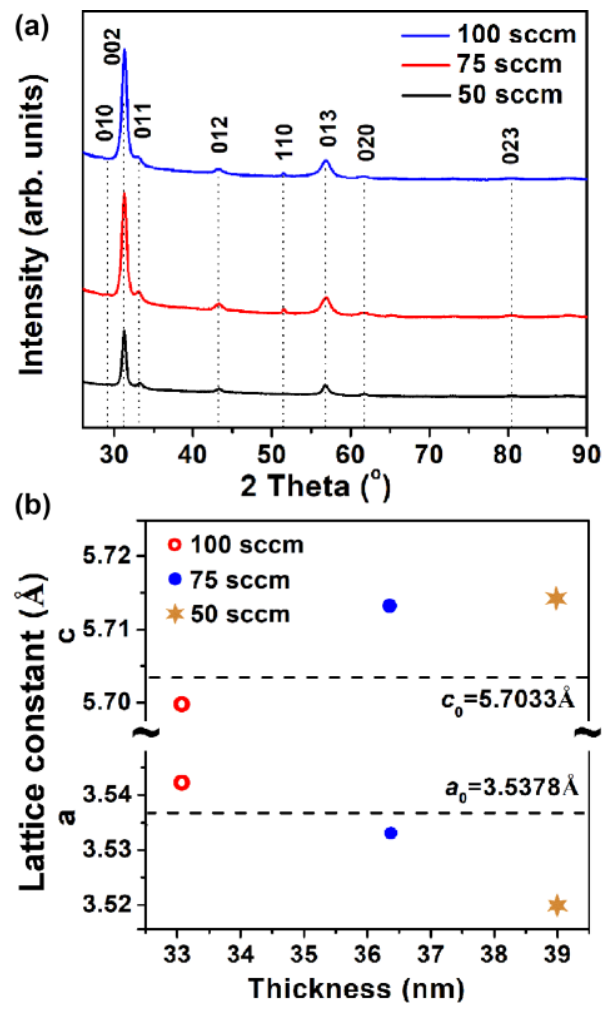

FIG. 8. GIXRD pattern (a) and variations of the $a$-and $c$-axis lattice constants (b) of InN film deposited on $\mathrm{Si}(100)$ substrate at $50 \mathrm{sccm}, 75 \mathrm{sccm}$ and $100 \mathrm{sccm}$ of $\mathrm{NH}_{3}$ flow with $2800 \mathrm{~W}$ plasma power at $320^{\circ} \mathrm{C}$. (More detailed information on peak intensities of GIXRD pattern is summarized in Fig. 1S). 
XPS measurements were conducted on $\mathrm{InN}$ thin films grown at $320{ }^{\circ} \mathrm{C}$ with and without a subsequent annealing at $500{ }^{\circ} \mathrm{C}$. Figure 9 shows the narrow scan XPS of In $3 \mathrm{~d}$ and $\mathrm{N} 1 \mathrm{~s}$ spectra for different growth and post-treatment temperatures which refer to the bulk film ( $\left.\mathrm{t}_{\mathrm{etch}}=400 \mathrm{~s}\right)$, and which is in agreement with previously reported values..$^{9,21}$ The surface of the InN film is oxidized and carbonized ( $30 \%$ oxygen and $\sim 25 \%$ carbon) is likely to originate from post-deposition exposure to atmosphere. For compositional depth profile measurements, InN thin films were etched by $\mathrm{Ar}^{+}$ions in steps of $400 \mathrm{~s}$ to obtain elemental composition from the bulk of the films. While carbon is detected on the films surface, the carbon signal is below the XPS detection limit in the bulk of the InN films. This is indicative of a well-functioning surface chemistry with the ammonia plasma, aiding in the removal of the methyl groups on the surface. ${ }^{22}$ Significant amounts of oxygen $(\mathrm{O})$ were detected in the bulk of the film, (Table I). This could be caused by oxygen containing species formed in the quartz tube of the inductively coupled plasma source. ${ }^{10}$ The polycrystalline nature of the films could also lead to oxidation of the film bulk via oxygen diffusion in grain boundaries. Figure 3a-d and Figure 6a show larger grain size and higher crystalline quality with higher deposition temperature, indicating that the lower oxygen content could be caused by less oxygen diffusion into the film with the larger crystallites. The $\mathrm{In} / \mathrm{N}$ ratio was computed from the composition of $\mathrm{InN}$ thin films (Table I) indicating nitrogen deficient films.

TABLE I. Elemental compositions (at.\%) and In/N ratios obtained from XPS survey spectra. The films are deposited with $2400 \mathrm{~W}$ plasma power and $50 \mathrm{sccm} \mathrm{NH}$ flow.

\begin{tabular}{|c|c|c|c|c|c|c|c|c|c|c|}
\hline \multirow[t]{2}{*}{$\begin{array}{c}\text { Deposition } \\
\text { temperature }\end{array}$} & \multicolumn{5}{|c|}{ Surface } & \multicolumn{5}{|c|}{ Bulk } \\
\hline & In & $\mathrm{N}$ & $\mathrm{O}$ & $\mathrm{C}$ & $\begin{array}{l}\mathrm{In} / \mathrm{N} \\
\text { Ratio }\end{array}$ & In & $\mathrm{N}$ & $\mathrm{O}$ & $\mathrm{C}$ & $\begin{array}{l}\mathrm{In} / \mathrm{N} \\
\text { Ratio }\end{array}$ \\
\hline $320^{\circ} \mathrm{C}$ & 29.3 & 18.7 & 27.1 & 24.8 & 1.57 & 47.5 & 28.9 & 23.6 & - & 1.64 \\
\hline $\begin{array}{l}320^{\circ} \mathrm{C} \text { annealed } \\
\text { at } 500^{\circ} \mathrm{C}\end{array}$ & 28.6 & 15.1 & 30.9 & 25.4 & 1.9 & 45.9 & 28.6 & 25.4 & - & 1.59 \\
\hline
\end{tabular}

The In 3d XPS spectrum (Fig. 9) show two spin-orbit doublets; In $3 \mathrm{~d}_{5 / 2}$ and In $3 \mathrm{~d}_{3 / 2}$ (with intensity ratio $3: 2$ ) for $\mathrm{InN}$ thin films grown at $320^{\circ} \mathrm{C}$ with and without a subsequent annealing at $500{ }^{\circ} \mathrm{C}$. The sub-peaks of the In $3 \mathrm{~d}_{5 / 2}$ and $\mathrm{In} 3 \mathrm{~d}_{3 / 2}$ correspond to In-N bonds and In-O bonds (Table II). The N 1s XPS spectrum reveal a dominant sub- 
peak corresponding to $\mathrm{N}$-In bonds which is more intense than the sub-peak corresponding to $\mathrm{N}-\mathrm{O}$ bonds. A slight shift from higher to lower binding energies for $\mathrm{N} 1 \mathrm{~s}$ peaks was observed when the deposition temperature was increased. This was correlated to the lower stress (higher crystallinity of $\mathrm{InN}$ ) and lower oxygen content in the $\mathrm{InN}$ film (Fig. 8a,b) and stoichiometries closer to 1:1 (In:N) ratio that were obtained at higher deposition temperatures.

TABLE II. Binding energies obtained from XPS survey spectra of InN in the bulk. ${ }^{9,21}$

\begin{tabular}{|c|c|c|c|c|c|c|}
\hline \multirow[t]{3}{*}{$\begin{array}{l}\text { Deposition } \\
\text { temperature }\end{array}$} & \multicolumn{6}{|c|}{ Binding energy, eV } \\
\hline & \multicolumn{2}{|c|}{ In-N } & \multicolumn{2}{|c|}{ In-O } & N-In & $\mathrm{N}-\mathrm{O}$ \\
\hline & In $3 d_{5 / 2}$ & In $3 d_{3 / 2}$ & In $3 d_{5 / 2}$ & In $3 d_{5 / 2}$ & \multicolumn{2}{|c|}{ N 1s } \\
\hline $320{ }^{\circ} \mathrm{C}$ & 443.6 & 451.1 & 444.3 & 451.6 & 396.4 & 396.8 \\
\hline $\begin{array}{l}320^{\circ} \mathrm{C} \text { annealed } \\
\text { at } 500^{\circ} \mathrm{C}\end{array}$ & 443.7 & 451.3 & 444.4 & 451.6 & 396.6 & 397.1 \\
\hline
\end{tabular}

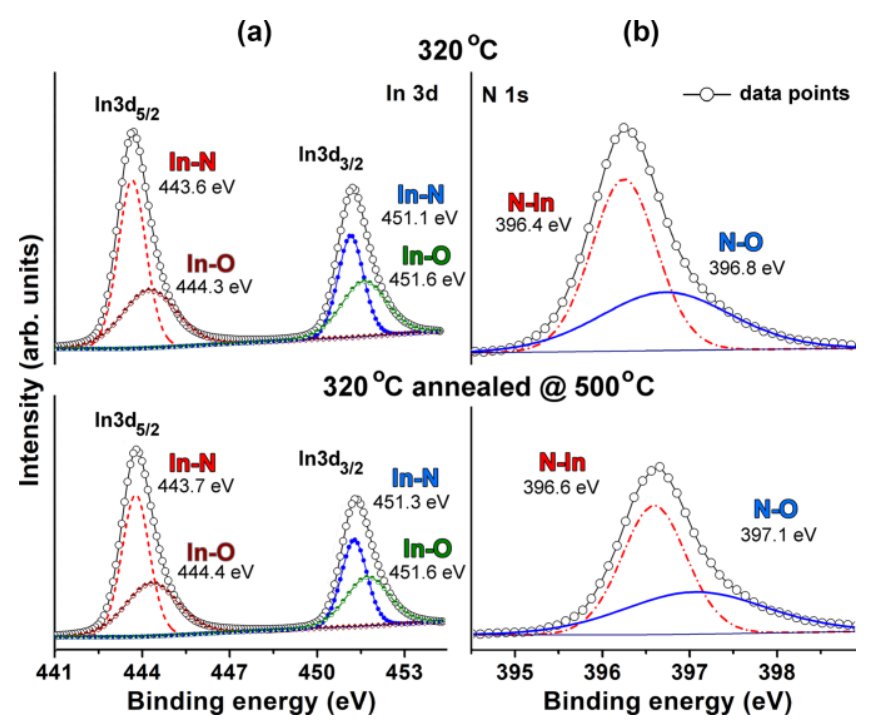

FIG. 9. High-resolution XPS spectra of (a) In 3d, (b) N 1s peaks of InN films deposited at temperatures. The spectra are taken after sputtering to represent the bulk of the films.

XPS measurements on InN films grown under $2800 \mathrm{~W}$ plasma power at $320^{\circ} \mathrm{C}$ show that a change in ammonia flow rate from $50 \mathrm{sccm}$ to $75 \mathrm{sccm}$ and further to $100 \mathrm{sccm}$, led to a significant reduction in oxygen content from $\sim 24$ at. $\%$ to $\sim 5$ at. $\%$ while the $\mathrm{N}$ content increased from $\sim 29$ at. $\%$ to $\sim 44$ at. $\%$. The $\mathrm{In} / \mathrm{N}$ ratio (Table III) indicating the shift from 
highly nitrogen deficient films with $\mathrm{In} / \mathrm{N}$ ratio of 1.64 (for $50 \mathrm{sccm}$ ammonia flow) to a stoichiometry closer to 1 with $\mathrm{In} / \mathrm{N}$ ratio of $\sim 1.1$ (for $75 \mathrm{sccm}$ and $100 \mathrm{sccm}$ ). The lower oxygen content in the film bulk could be caused by the slightly larger crystalline grains formed with higher ammonia flow (Fig. 5a-c), which would lead to less grain boundary diffusion of oxygen. (Fig. 8). Another plausible reason for the lower oxygen content in the film bulk could be that the higher ammonia flow would reduce the impact of any oxygen containing species in the plasma discharge since a higher ammonia flow would render a lower partial pressure of the oxygen containing species. Haider, et al. for the ALD process with $\mathrm{N}_{2}$ plasma after XPS analysis of $\mathrm{InN}$ films in the bulk have shown elemental composition of In ( 65.0 at. \%), N ( 29.8 at. \%), $\mathrm{O}(\sim 2.1$ at. \%), C ( 3 at. \%) and $\mathrm{In} / \mathrm{N}$ ration 2.17. ${ }^{9}$ Nepal et al., for the ALD process with $\mathrm{N}_{2}$ plasma have shown that the In/N ratio is 1.46 at $260{ }^{\circ} \mathrm{C} .{ }^{11}$ The $\mathrm{In} / \mathrm{N}$ ratio of $2.8 \pm 0.7$ has been reported on MBE grown InN. ${ }^{23}$ Thus, the InN film grown in our study using $\mathrm{NH}_{3}$ plasma has much better stoichiometry compared to $\mathrm{MBE}$ grown $\mathrm{InN}$, better stoichiometry compared to $\mathrm{N}_{2}$ plasma-assisted ALD processes reported by Haider et. al. and Nepal et al. at higher temperatures, and comparable stoichiometry compared to the values reported by Nepal et al. for InN grown at $190^{\circ} \mathrm{C}$.

Table III. Elemental compositions (at.\%) and In/N ratios obtained from XPS survey spectra. The films are deposited with $2800 \mathrm{~W}$ plasma power.

\begin{tabular}{|c|c|c|c|c|c|c|c|c|c|c|}
\hline \multirow[t]{2}{*}{$\begin{array}{l}\begin{array}{l}\text { Deposition } \\
\text { temperature }\end{array} \\
\end{array}$} & \multicolumn{5}{|c|}{ Surface } & \multicolumn{5}{|c|}{ Bulk } \\
\hline & In & $\mathrm{N}$ & $\mathrm{O}$ & $\mathrm{C}$ & $\begin{array}{l}\text { In/N } \\
\text { Ratio }\end{array}$ & In & $\mathrm{N}$ & $\mathrm{O}$ & $\mathrm{C}$ & $\begin{array}{l}\mathrm{In} / \mathrm{N} \\
\text { Ratio }\end{array}$ \\
\hline $50 \mathrm{sccm}$ & 29.3 & 18.7 & 27.1 & 24.8 & 1.57 & 47.5 & 28.9 & 23.5 & - & 1.64 \\
\hline $75 \mathrm{sccm}$ & 22.9 & 21.7 & 25.8 & 29.4 & 1.05 & 46.2 & 41.2 & 11.5 & 1.0 & 1.12 \\
\hline $100 \mathrm{sccm}$ & 23.9 & 22.5 & 25.3 & 28.2 & 1.06 & 50.8 & 43.8 & 4.8 & 0.53 & 1.15 \\
\hline
\end{tabular}

In $3 d$ XPS spectrum (Fig. 10) again show two spin-orbit doublets; In $3 d_{5 / 2}$ and In $3 d_{3 / 2}$ for $\mathrm{InN}$ thin films grown at $50 \mathrm{sccm}, 75 \mathrm{sccm}, 100 \mathrm{sccm}$ of ammonia flow. The sub-peaks of the In $3 \mathrm{~d}_{5 / 2}$ and $\mathrm{In} 3 \mathrm{~d}_{3 / 2}$ correspond to In-N and In-O bonds (Table IV). The $\mathrm{N} 1 \mathrm{~s}$ XPS spectrum reveal a dominant sub-peak corresponding to N-In bonds which is more intense than the subpeak corresponding to $\mathrm{N}-\mathrm{O}$ bonds. The binding energies as a function of different ammonia flow show slight shift to lower energies for peaks corresponding to $\mathrm{In}-\mathrm{N}$ bonds. This is correlated to the lower oxygen content in the InN film for higher ammonia flow. 


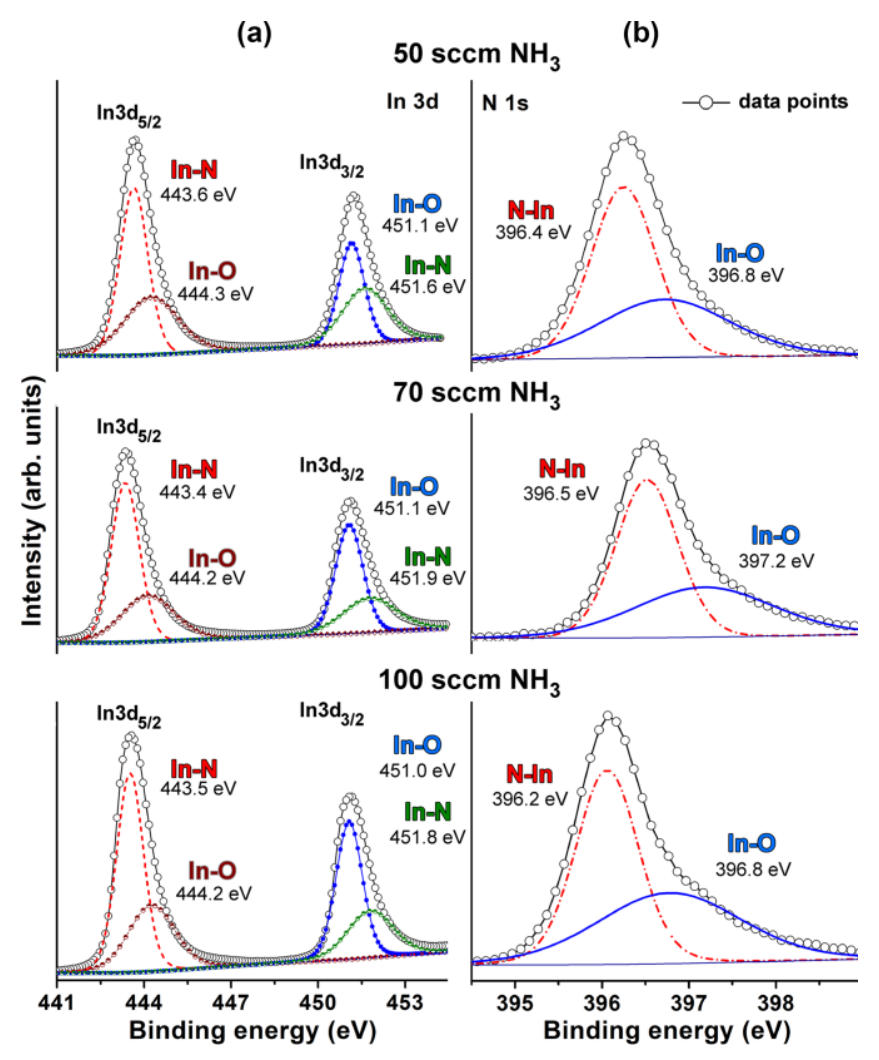

FIG. 10. High-resolution XPS spectra of (a) In 3d, (b) $\mathrm{N}$ 1s peaks of InN films deposited with $50 \mathrm{sccm}, 75 \mathrm{sccm}, 100 \mathrm{sccm}$ of ammonia flow at $320^{\circ} \mathrm{C}$ and $2800 \mathrm{~W}$ of plasma power. The spectra are taken after sputtering to represent the analysis of $\mathrm{InN}$ in the bulk.

Table IV. Binding energies obtained from XPS survey spectra of InN in the bulk. ${ }^{9,21}$

\begin{tabular}{|c|c|c|c|c|c|c|}
\hline \multirow[t]{2}{*}{$\mathrm{NH}_{3}$ flow rate } & \multicolumn{6}{|c|}{ Binding energy, eV } \\
\hline & \multicolumn{2}{|c|}{$\begin{array}{l}\text { In-N } \\
\text { In } 3 d_{5 / 2}\end{array}$} & \multicolumn{2}{|c|}{$\begin{array}{c}\text { In-O } \\
\text { In } 3 d_{3 / 2}\end{array}$} & $\begin{array}{l}\text { N-In } \\
\text { In } 3 d_{5 / 2}\end{array}$ & $\begin{array}{c}\mathrm{N}-\mathrm{O} \\
\text { In } 3 \mathrm{~d}_{5 / 2}\end{array}$ \\
\hline $50 \mathrm{sccm}$ & 443.6 & 451.1 & 444.3 & 451.6 & 396.4 & 396.8 \\
\hline $75 \mathrm{sccm}$ & 443.4 & 451.1 & 444.2 & 451.9 & 396.5 & 397.2 \\
\hline $100 \mathrm{sccm}$ & 443.5 & 451.0 & 444.2 & 451.8 & 396.2 & 396.8 \\
\hline
\end{tabular}

To further understand the deposition process, we collected OES spectra during InN deposition at $320^{\circ} \mathrm{C}$ with plasma powers of $2400 \mathrm{~W}$ and $2800 \mathrm{~W}$ and with $\mathrm{NH}_{3}$ flow rates of $50 \mathrm{sccm}, 75 \mathrm{sccm}$ and $100 \mathrm{sccm}$. A carrier flow of $100 \mathrm{sccm}$ Ar was used for all experiments (see Fig. 11 and Table V). The emission spectra for the $2400 \mathrm{~W}$ and $2800 \mathrm{~W}$ of $\mathrm{NH}_{3}$ plasmas were found to be very similar with the same peaks positions and almost the same peaks intensities. The prominent lines were observed as a line related to $\mathrm{NH}$ at 
$336.1 \mathrm{~nm}$, a line related to $\mathrm{N}_{2}$ at $357.1 \mathrm{~nm}$, a shoulder related to $\mathrm{CN}$ at $388.5 \mathrm{~nm}$, and a line related to $\mathrm{N}_{2}{ }^{+}$at $391.4 \mathrm{~nm}$. The $\mathrm{NH}, \mathrm{N}_{2}$, and $\mathrm{N}_{2}{ }^{+}$species were not observed to increase with increased plasma power but with increased $\mathrm{NH}_{3}$ flow rate (Fig. 11a, and Fig. 11b). The emission peaks at $\sim 336 \mathrm{~nm}$ and $337 \mathrm{~nm}$ for different plasma power and $\mathrm{NH}_{3} / \mathrm{Ar}$ flow rate, indicate the presence of the excited $\mathrm{NH}, \mathrm{N}_{2}$ radicals that corresponds to $\mathrm{A}^{3} \Pi \rightarrow \mathrm{X}^{3} \Sigma$ and $\mathrm{C}^{3} \Pi_{\mathrm{u}} \rightarrow \mathrm{B}^{3} \Pi_{\mathrm{g}}$ transitions, corroborating the presence of $\mathrm{NH}_{\mathrm{x}}(\mathrm{x}<3)$ and $\mathrm{N}_{2}$ species. ${ }^{24,25} \mathrm{In}$ addition to $\mathrm{NH}, \mathrm{N}_{2}, \mathrm{~N}_{2}{ }^{+}$, and $\mathrm{CN}$ detected in $\mathrm{NH}_{3} / A r$ plasma, the $\mathrm{H}_{\gamma}, \mathrm{H}_{\beta}$, and $\mathrm{H}_{\alpha}$ lines were detected at $434.0 \mathrm{~nm}, 486.1 \mathrm{~nm}$, and $\sim 656.3 \mathrm{~nm}$ (Table V). The presence of $\mathrm{N}_{2}, \mathrm{~N}_{2}{ }^{+}$and $\mathrm{H}$ radicals can be attributed to the collisions of $\mathrm{NH}$ radicals: $\mathrm{NH}+\mathrm{NH} \rightarrow \mathrm{N}_{2}+2 \mathrm{H}\left(k=1.2 \times 10^{-}\right.$ $\left.{ }^{15} \mathrm{~m}^{3} \mathrm{~s}^{-1}\right) .{ }^{26} \mathrm{CN}$ species are attributed to the plasma-surface interactions; species created at the surface in reactions with the ammonia plasma and surface bound methyl groups, which are then further decomposed in the plasma making them visible as $\mathrm{CN}$ in OES measurement, and then removed from the chamber during the purge step. ${ }^{27}$ The OES measurements could not find any optically active oxygen containing species and can thus not confirm any formation of oxygen containing species in the plasma discharge in the quartz tube. It is important to note that the OES measurements only detect optically active species and possible oxygen containing species might not be optically active. The OES measurements are thus not suggesting that oxygen containing species are not formed in the plasma discharge.

Table V. Spectral characteristics of species detected in the $\mathrm{NH}_{3} / \mathrm{Ar}$ plasma.

\begin{tabular}{|c|c|c|c|c|c|}
\hline Species & \multicolumn{3}{|c|}{$\lambda, \mathbf{n m}$} & Transition & "Reference \\
\hline NH & 336.1 & & & $\mathrm{~A}^{3} \Pi \rightarrow \mathrm{X}^{3} \Sigma^{-}(3360 \AA$ system $)$ & 24 \\
\hline $\mathbf{N}_{2}$ & 337.1, & 357.7 & & $\mathrm{C}^{3} \Pi_{\mathrm{u}} \rightarrow \mathrm{B}^{3} \Pi_{\mathrm{g}}$ Second positive & $24,28,29$ \\
\hline $\mathbf{N}_{2}{ }^{+}$ & 391.4, & 427.6 & & $\mathrm{~B}^{2} \Sigma_{\mathrm{u}}^{+} \rightarrow \mathrm{X}^{2} \Sigma_{\mathrm{g}}^{+}$ & 24,28 \\
\hline $\mathbf{C N}$ & 388.88 & & & $\mathrm{~B}^{2} \Sigma_{\mathrm{u}}{ }^{+} \rightarrow \mathrm{X}^{2} \Sigma_{\mathrm{g}}^{+}$ & 28,30 \\
\hline \multirow[t]{3}{*}{$\mathbf{H}_{\gamma}, \mathbf{H}_{\beta}, \mathbf{H}_{\alpha}$} & 434.0, & 486.1, & 656.29 & $\mathrm{n}(>2) \rightarrow \mathrm{n}=2$ (Balmer line $)$ & \multirow[t]{3}{*}{29} \\
\hline & 695.6, & 750.3, & 911.1 & $4 \mathrm{p}^{2}[1 / 2] \rightarrow 4 \mathrm{~s}^{2}[3 / 2]^{0}$ & \\
\hline & 705.9, & 738.0 & 763.48 & $4 \mathrm{p}^{2}[3 / 2] \rightarrow 4 \mathrm{~s}^{2}[3 / 2]^{0}$ & \\
\hline \multirow[t]{3}{*}{ Ar } & 772.5 & 827.3 & & $4 \mathrm{p}^{2}[1 / 2] \rightarrow 4 \mathrm{~s}^{2}[1 / 2]^{0}$ & \multirow[t]{3}{*}{28} \\
\hline & 795.2 & & & $4 \mathrm{p}^{2}[3 / 2] \rightarrow 4 \mathrm{~s}^{2}[1 / 2]^{0}$ & \\
\hline & 801.7 & 811.6, & 842.2 & $4 p^{2}[5 / 2] \rightarrow 4 s^{2}[3 / 2]^{0}$ & \\
\hline
\end{tabular}



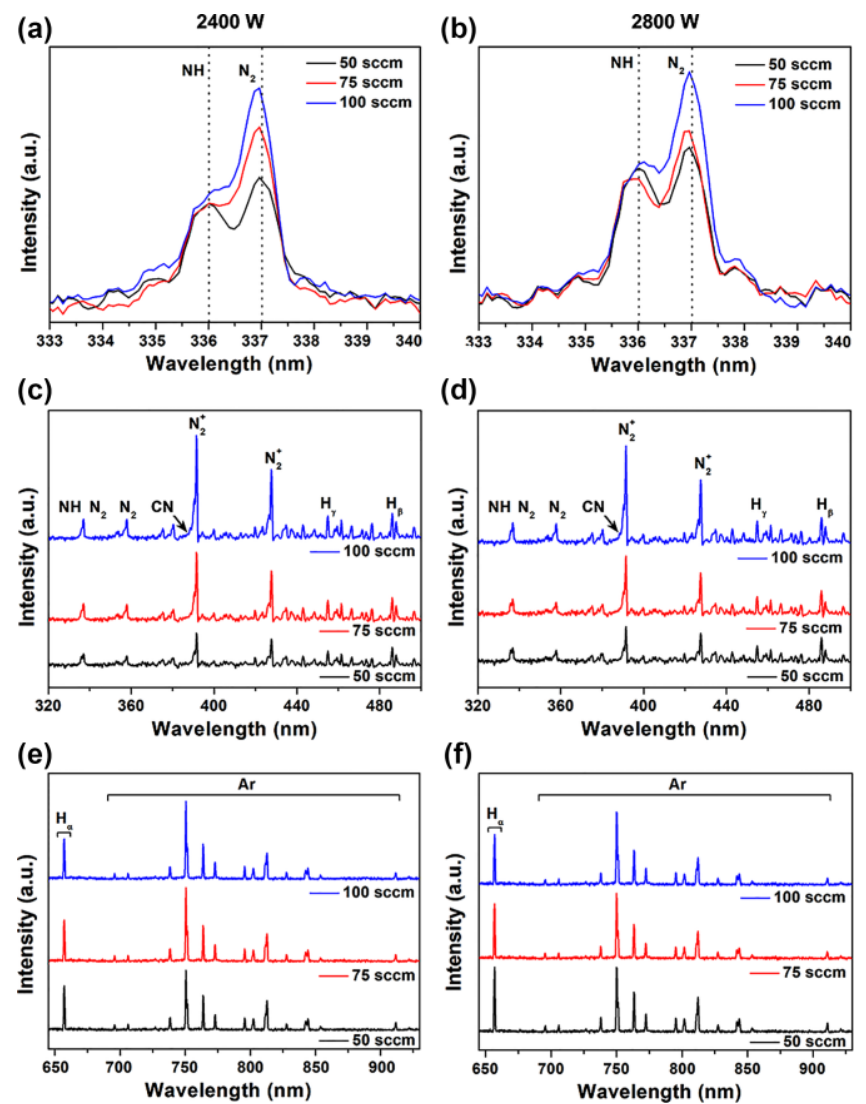

FIG. 11. Optical emission spectra for $\mathrm{NH}_{3}$ and $\mathrm{Ar}$ plasmas at $2400 \mathrm{~W}, 2800 \mathrm{~W}$ and $50 \mathrm{sccm}, 75 \mathrm{sccm}$, and $100 \mathrm{sccm}$ of $\mathrm{NH}_{3}$ over the wavelength range of (a, b) $333 \mathrm{~nm}-$ $340 \mathrm{~nm},(\mathrm{c}, \mathrm{d}) 320 \mathrm{~nm}-500 \mathrm{~nm}$, and (e, f) $645 \mathrm{~nm}-930 \mathrm{~nm}$.

InN thin film $\left(\sim 39 \mathrm{~nm}\right.$ thick) grown at $320^{\circ} \mathrm{C}$ and $2800 \mathrm{~W}$ was studied by Raman scattering measurements (Fig. 12). Reference spectra from bare Si substrate are also displayed for comparison (bottom curves in each panel). Expanded views of the spectral regions $150-490 \mathrm{~cm}^{-1}$, and $530-650 \mathrm{~cm}^{-1}$ are shown in Figure $12(\mathrm{a}-\mathrm{d})$. According to the factor group analysis six optical modes can be observed for crystalline InN in the first-order Raman spectrum: $\mathrm{A}_{1}(\mathrm{TO}), \mathrm{A}_{1}(\mathrm{LO}), \mathrm{E}_{1}(\mathrm{TO}), \mathrm{E}_{1}(\mathrm{LO}), \mathrm{E}_{2}$ (high), and $\mathrm{E}_{2}$ (low). ${ }^{31}$ In our Raman scattering experiments, the $\mathrm{A}_{1}(\mathrm{TO})$ and $\mathrm{A}_{1}(\mathrm{LO})$ modes of hexagonal InN were observed at wave numbers of $447 \mathrm{~cm}^{-1}$ and $586 \mathrm{~cm}^{-1}$ together with peaks ascribed to yet unidentified defects at $180 \mathrm{~cm}^{-1}$ and $375 \mathrm{~cm}^{-1} \cdot 32,33$ The band peaking at $436 \mathrm{~cm}^{-1}$ is due to second-order Raman scattering from the Si substrate. ${ }^{34}$ The sharp rise in parts $(c, d)$ of the Figure 12 is due to the wings of the strong Raman 
peak of the substrate at $520 \mathrm{~cm}^{-1}$. Furthermore, the Si-substrate related mode at $520 \mathrm{~cm}^{-}$ ${ }^{1}$ has obviously shoulders on the left- and right-hand side that covers the broad range from $\sim 460 \mathrm{~cm}^{-1}$ to $\sim 580 \mathrm{~cm}^{-1}$ where other phonon modes such as $\mathrm{E}_{1}$ (TO), $\mathrm{E}_{2}^{\text {high }}$ could exist. ${ }^{35-37}$ Thereby, the Raman spectra also support that crystalline $\mathrm{InN}$ dominated by hexagonal phase was grown on $\mathrm{Si}$.
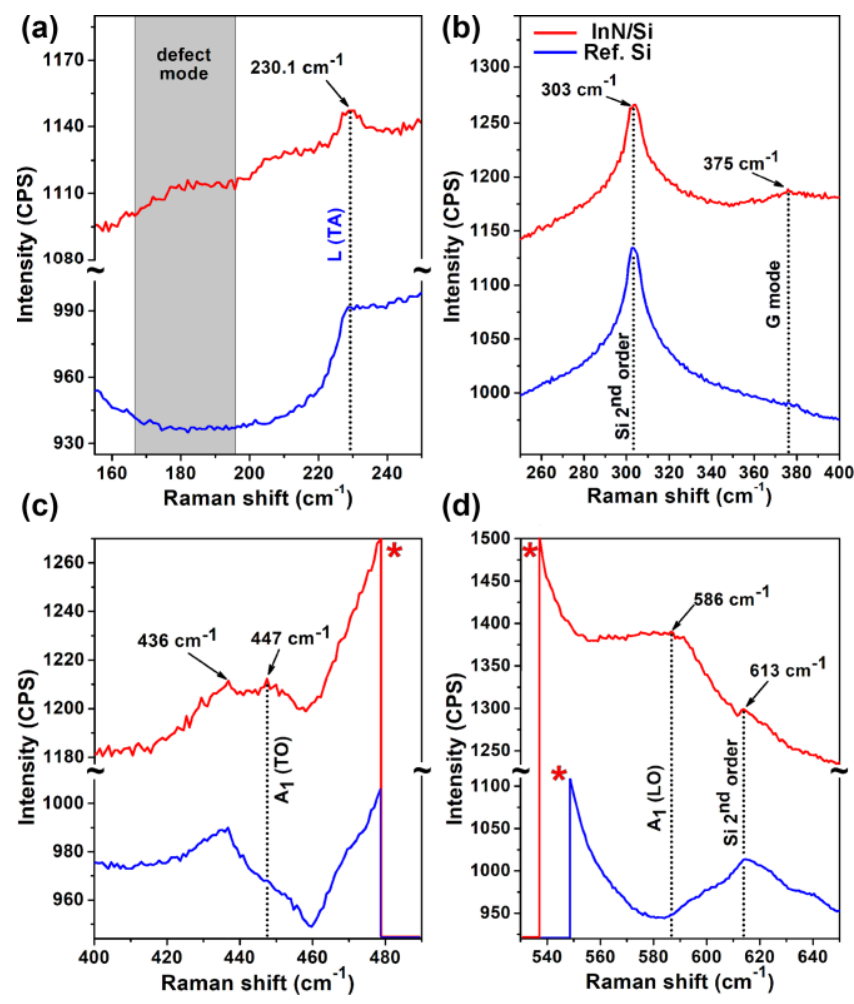

FIG. 12. Raman spectra of $\mathrm{InN}$ film grown at $320^{\circ} \mathrm{C}$ and $2800 \mathrm{~W}$ of ammonia plasma for 150-250 cm $\mathrm{cm}^{-1}$ (a), $250-400 \mathrm{~cm}^{-1}$ (b), $400-490 \mathrm{~cm}^{-1}$ (c), and $530-650 \mathrm{~cm}^{-1}$ (d). Two prominent modes typical for wurtzite h-InN structure are observed. $(*$ denotes peak from the $\mathrm{Si}$ substrate). The bottom curve in each panel displays the spectrum of bare $\mathrm{Si}$ substrate in the corresponding region, which serves as a reference.

Using ellipsometric spectroscopy, we obtained refractive index $(n)$ and extinction coefficient $(k)$ of InN films deposited at $320^{\circ} \mathrm{C}$ and $360^{\circ} \mathrm{C}$ (Fig. 13a). Refractive index was measured to be 2.6 and 2.7 at $650 \mathrm{~nm}$, while it was measured to be 1.95 and 2.03 at $1400 \mathrm{~nm}$, respectively. These values are in good agreement with the reported values for polycrystalline h-InN thin films. ${ }^{9,38}$ An increase in thickness of InN from $39 \mathrm{~nm}$ to $48 \mathrm{~nm}$ leads to an increase in refractive index by 0.1 and 0.08 at $650 \mathrm{~nm}$ 
and $1400 \mathrm{~nm}$, respectively. This improvement might be attributed to film densification with the increase in thickness of the film. Extinction coefficient $(k)$ of $\mathrm{InN}$ films, measured to be 0.36 and 0.41 at $600 \mathrm{~nm}$, these values decrease drastically within the wavelength range of $600-900 \mathrm{~nm}$, and reaches rather insignificant level at longer wavelengths.

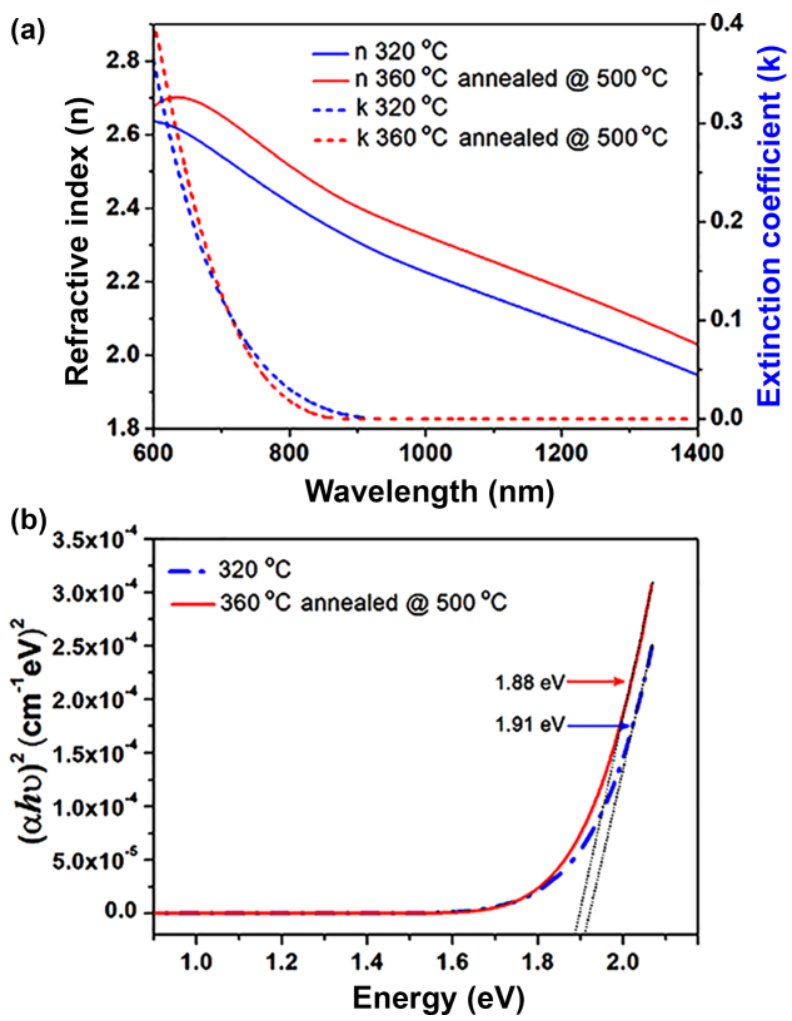

FIG. 13. (a) Optical constants $\mathrm{n}$ and $\mathrm{k}$ of $\mathrm{InN}$ thin film deposited on $\mathrm{Si}(100)$ at $320^{\circ} \mathrm{C}$ and $360^{\circ} \mathrm{C}$. (b) Absorption spectra of the same InN samples.

Figure 13(b) shows $(\alpha h v)^{2}$ vs. hv plot, which is obtained from spectroscopic ellipsometry measurement and related data analysis as explained in the experimental section. Straight line segment of the plot was extrapolated to the abscissa (black arrows shown in the inset of Fig. 13b) which reveals the band edge of InN thin films as $1.91 \mathrm{eV}$ and $1.88 \mathrm{eV}$ at $320^{\circ} \mathrm{C}$ and $360^{\circ} \mathrm{C}$. These results are in a good agreement to the results $(1.9 \mathrm{eV})$ obtained for InN thin films grown via ALD using TMI and $\mathrm{N}_{2}$ plasma. ${ }^{9}$ 


\section{IV.SUMMARY AND CONCLUSIONS}

We show the development of a self-limiting $\mathrm{InN}$ growth process utilizing trimethylindium and ammonia plasma in a remote plasma ALD system at $240-360^{\circ} \mathrm{C}$ and $2400-2800 \mathrm{~W}$ plasma power. We find a narrow thermal ALD window between $240{ }^{\circ} \mathrm{C}$ and $260^{\circ} \mathrm{C}$ with a growth rate of $0.36 \AA$.cycle. The crystalline quality of the $\mathrm{InN}$ was found to improve significantly with temperature and self-limiting deposition chemistry was demonstrated also at $320^{\circ} \mathrm{C}$. The deposited InN films at $320^{\circ} \mathrm{C}, 2800 \mathrm{~W}$ and $100 \mathrm{sccm}$ of $\mathrm{NH}_{3}$ flow are polycrystalline by GIXRD with carbon content below 1 at. $\%$ and oxygen level below 5 at. $\%$ in the film bulk, indicative of a well-functioning ALD surface chemistry. The InN films were found to be nearly stoichiometric by XPS with $\mathrm{In} / \mathrm{N}$ ratio of 1.1. We ascribe the film bulk oxygen content to film oxidation caused by grain boundary diffusion of oxygen upon exposure to air and possibly also by oxygen containing species possibly formed in the plasma discharge done in a quartz tube. The ammonia plasma was found to contain $\mathrm{NH}, \mathrm{CN}, \mathrm{N}_{2}, \mathrm{~N}_{2}{ }^{+}$and hydrogen radicals by OES. We find that the $\mathrm{NH}_{3}$ flow through the plasma discharge is an important parameter for depositing films with high crystalline quality and low impurity levels. The refractive index of the $\mathrm{InN}$ films was measured to be 2.7 at $650 \mathrm{~nm}$, and 2 at $1400 \mathrm{~nm}$, respectively. The optical band gap of the InN films was measured to about $1.9 \mathrm{eV}$.

\section{ACKNOWLEDGMENTS}

This project was founded by the Swedish foundation for Strategic Research through the project "Time-resolved low temperature CVD for III-nitrides" (SSF-RMA 15-0018) and by the Knut and Alice Wallenberg foundation through the project "Bridging the $\mathrm{THz}$ gap" (KAW 2013.0049). IGI acknowledges support from the VR (project VR 201605362). PD acknowledges the Carl Trygger Foundation for a post-doctoral scholarship at Linköping University and Laurent Souqui for his kind suggestions during OES measurements. 
${ }^{1}$ A. G. Bhuiyan, A. Hashimoto, and A. Yamamoto, J. Appl. Phys. 94, 2779 (2003).

${ }^{2}$ B. A. Andreev, K. E. Kudryavtsev, A. N. Yablonskiy, D. N. Lobanov, P. A. Bushuykin, L. V. Krasilnikova, E. V. Skorokhodov, P. A. Yunin, A. V. Novikov, V. Yu Davydov \& Z. F. Krasilnik, Scientific Reports 8, 9454 (2018).

${ }^{3}$ S. V. Ivanov, T. V. Shubina, V. N. Jmerik, J. Crystal Growth 403, 83 (2014).

${ }^{4}$ J. Y. Hwang, C. Park, J. H. Jung, and T. J. Anderson, Journal of The Electrochemical Society 155 (2), H124 (2008).

${ }^{5}$ K. Rönnby, S. C. Buttera, P. Rouf, S. Barry, L. Ojamäe, and H. Pedersen, (2018). Preprint https://doi.org/10.26434/chemrxiv.7067687.v1

${ }^{6}$ S. Ruffenach, M. Moret, O. Briot, and B. Gil, Phys. Status Solidi A 207, 9 (2010).

${ }^{7}$ H. Peng, X. Feng, J. Gong, W. Wang, H. Liu, Z. Quan, S. Pan, L. Wang, Applied Surface Science 459, 830 (2018).

${ }^{8}$ A. Haider, P. Deminskyi, M. Yilmaz, K. Elmabruk, I. Yilmazd, and N. Biyikli, J. Mater. Chem. C 6, 6471 (2018).

${ }^{9}$ A. Haider, S. Kizir, N. Biyikli, AIP Adv. 6, 045203 (2016).

${ }^{10}$ D. Boris, V. Anderson, N. Nepal, S. Johnson, Z. Robinson, A. Kozen, C. Eddy Jr., and S. Walton, J. Vac. Sci. Technol. A 36, 5 (2018).

${ }^{11}$ N. Nepal, N. Mahadik, L. Nyakiti, S. B. Qadri, M. J. Meh, J. Hite, and C. Eddy, Jr., Crystal Growth \& Design 13, 1485 (2013).

${ }^{12}$ C. Ozgit-Akgun, E. Goldenberg, S. Bolat, B. Tekcan, F. Kayaci, T. Uyar, A. K. Okyay, N. Biyikli, Phys. Status Solidi C 12, 3942123 (2015).

${ }^{13}$ M. F. J. Vos, G. Straaten, W. M. M. Kessels, and A. J. M. Mackus, J. Phys. Chem. C 122 (39), 22519 (2018).

${ }^{14}$ D. Shenai-Khatkhate, R. L. DiCarlo, R. A. Ware, J. Cryst. Growth 310, 2395 (2008).

${ }^{15}$ A. Koukitu, T. Taki, N. Takahashi, and H. Seki, J. Cryst. Growth 197, 99 (1999).

${ }^{16}$ A. Haider, S. Kizir, C. Ozgit-Akgun, A. K. Okyay, N. Biyikli, J. Vac. Sci. Technol. A, 34, 1 (2016). 
${ }^{17}$ W. Paszkowicz, R. Černý, and S. Krukowski, Powder Diffr. 18, 2 (2003).

${ }^{18}$ I. Yonenaga, M. Deura, X. Q. Wang et al., AIP Advances 5, 077131 (2015).

${ }^{19}$ A. Zubrilov, In Properties of Advanced Semiconductor Materials GaN, AlN, InN, BN, SiC, SiGe, (John Wiley \& Sons Inc., New York, 2001) p. 49.

${ }^{20}$ G. X. Ju, S. Fuchi, M. Tabuchi, and Y. Takeda: J. Cryst. Growth 370, 36 (2013).

${ }^{21}$ A. Conde, A.B. Cristóbal, G. Fuentes, T. Tate, J. de Damborenea, Surface \& Coatings Technology 201, 3588 (2006).

${ }^{22}$ C. Cheng, S. Lucas, H. Gutleben, W. Choyke, and J. Yates, Surface Science Letters 273, L441 (1992).

${ }^{23}$ L. Piper, T. Veal, M. Walker, I. Mahboob, C. McConville, H. Lu, W. Schaff, J. Vac. Sci. Technol. A 23, 617 (2005).

${ }^{24}$ R. Bazinette, J. Paillol, F. Massines, Plasma Sources Sci. Technol. 24, 055021 (2015).

${ }^{25}$ L. Yan-qin, B. De-cai, D. Lan-bo, Z. Xiu-ling, L. Zhi-sheng, L. Xue-hui, Spectroscopy and spectral analysis 35, 765 (2015).

${ }^{26}$ M. Boumerzoug, P. Mascher, P. Mascher, Plasma Chemistry and Plasma Processing 17, 2 (1997).

${ }^{27}$ C. Vandenabeele, M. Buddhadasa, P. Girard-Lauriault, R. Snyders, Thin Solid Films 630, 100 (2017).

${ }^{28}$ R. DiMundo, F. Palumbo, F. Fracassi, R. d'Agostino, Plasma Processes and Polym. 4, S21 (2007).

${ }^{29}$ A. Koukitu, N. Takahashi, and H. Seki, Jpn. J. Appl. Phys. 36, 136 (1997).

${ }^{30}$ S. Sarapiroma, L. Yua, D. Boonyawana, C. Chaiwonga, Applied Surface Science 310, 42 (2014).

${ }^{31}$ C. A. Arguello, D. L. Rousseau, and S. P. S. Porto, Physical Review 181, 1351 (1969).

${ }^{32}$ M. Yoshimoto, Y. Yamamoto, and J. Saraie, Phys. Stat. Sol. 7, 2794 (2003).

${ }^{33}$ J. Wang, Z. Li, P. Chen, W. Lu, T. Yao, Acta Materialia 55, 183 (2007). 
${ }^{34}$ A. V. Kolobov J. Applied Physics 87, 2926 (2000).

${ }^{35}$ M. Liebhaber, B. Halbig, U. Bass, and J. Geurts, Phys. Rev. B 94, 235304 (2016).

${ }^{36}$ J. Bohn, P. Etchegoin, E. Le Ru, R. Xiang, S. Chiashi, and S. Maruyama, ACS Nano 4, 3466 (2010).

${ }^{37}$ K. Torii, N. Usukura, A, Nakamura, T. Sota, S. Chichibu, T. Kitamura, and H.

Okumura, Appl. Phys. Lett. 82, 6 (2003).

${ }^{38}$ L. F. Jiang, W. Z. Shen, H. F. Yang, H. Ogawa, Q. X. Guo, Appl. Phys. A 78, 89 (2004). 


\title{
Supplementary material for:
}

\section{Atomic layer deposition of InN using trimethylindium and ammonia plasma}

\author{
Petro Deminskyia), Polla Rouf, Ivan G. Ivanov, Henrik Pedersen
}

Department of Physics, Chemistry and Biology, Linköping University, SE-58183 Linköping, Sweden

a) Electronic mail: petro.deminskyi@liu.se
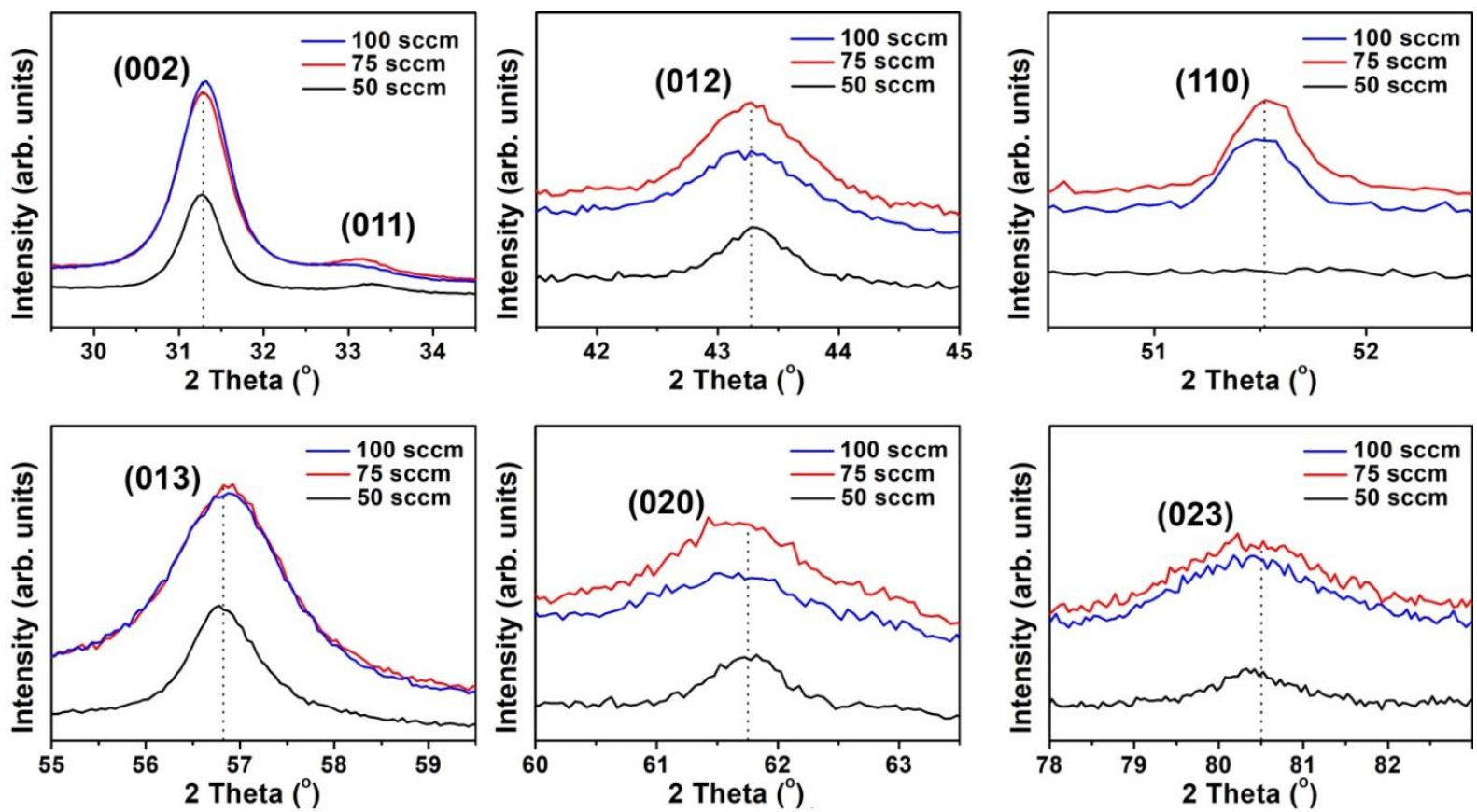

FIG. S1. GIXRD patterns of InN films deposited with different $\mathrm{NH}_{3}$ flow.

More detailed investigation on GIXRD pattern of $\mathrm{InN}$ films deposited with different $\mathrm{NH}_{3}$ flow (Fig. S1), reveals that:

(1) Peaks intensity increasing significantly with increasing $\mathrm{NH}_{3}$ flow from $50 \mathrm{sccm}$ to $75 \mathrm{sccm}$.

(2) With further increasing of $\mathrm{NH}_{3}$ flow from $75 \mathrm{sccm}$ to $100 \mathrm{sccm}$, the intensity further slightly increasing for (002) peak only, and slightly decreasing for all other peaks (012), (110), (013), (020), (023).

It could be explained with the grains reorientation to more preferable 002 crystal plane. 
TABLE S1. $a$ - and $c$-axis lattice parameters of InN grown at different growth conditions.

\begin{tabular}{|c|c|c|c|}
\hline Growth parameters & & $\begin{array}{c}\text { c-axis } \\
\text { lattice } \\
\text { parameter }\end{array}$ & $\begin{array}{c}\text { a-axis } \\
\text { lattice } \\
\text { parameter }\end{array}$ \\
\hline \multicolumn{4}{|l|}{ 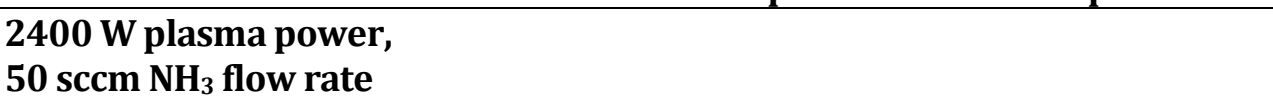 } \\
\hline & $240^{\circ} \mathrm{C}$ & 5.7310 & 3.5295 \\
\hline & $320^{\circ} \mathrm{C}$ & 5.7227 & 3.5311 \\
\hline & $360^{\circ} \mathrm{C}$ & 5.7225 & 3.5310 \\
\hline \multicolumn{4}{|l|}{$50 \mathrm{sccm} \mathrm{NH}_{3}$ plow rate, $320{ }^{\circ} \mathrm{C}$} \\
\hline & $2400 \mathrm{~W}$ & 5.7225 & 3.5450 \\
\hline & $2500 \mathrm{~W}$ & 5.7224 & 3.5295 \\
\hline & $2800 \mathrm{~W}$ & 5.7143 & 3.532 \\
\hline \multicolumn{4}{|l|}{$2800 \mathrm{~W}$ plasma power, $320 \stackrel{\circ}{ } \mathrm{C}$} \\
\hline & $50 \mathrm{sccm}$ & & \\
\hline & $100 \mathrm{sccm}$ & & 3.54271 \\
\hline $\begin{array}{l}2800 \mathrm{~W} \text { plasma power, } 50 \\
\text { sccm } \mathrm{NH}_{3} \text { flow rate, } \\
\text { annealed at } 500{ }^{\circ} \mathrm{C} \text {, }\end{array}$ & & & \\
\hline
\end{tabular}

